\title{
Congenital hypothyroidism with gland in situ is more frequent than previously thought
}

\author{
Luca Persani ${ }^{1,2,3 *}$ \\ Department of Medical Sciences, University of Milan, Milan, Italy \\ Division of Endocrinology and Metabolism, IRCCS Istituto Auxologico Italiano, Milan, Italy \\ 3 Laboratory of Endocrine and Metabolic Research, IRCCS Istituto Auxologico Italiano, Milan, Italy \\ *Correspondence: luca.persani@unimi.it
}

Congenital hypothyroidism $(\mathrm{CH})$ is the most common congenital endocrine disease and avoidable cause of severe mental retardation. L-thyroxine supplementation started within 2-3 weeks of age can prevent severe neurological damage. Thus, neonatal screening programs have been instituted to allow early $\mathrm{CH}$ detection and initiation of therapy and still represent one of the major achievements of preventive medicine.

The use of different strategies has allowed the early detection of a larger number of $\mathrm{CH}$ cases, with a reported incidence of 1:3,000-4,000 newborns during the last decades of the twentieth century (Dussault, 1999; Van Vliet and Czernichow, 2004; Rose et al., 2006; Rastogi and LaFranchi, 2010). Surprisingly, more recent observational studies reported an incidence reaching about 1:1,500 live newborns (Harris and Pass, 2007; Corbetta et al., 2009; Rastogi and LaFranchi, 2010). These studies were originally performed in New York State and in Lombardy (Italy) using two different screening strategies: T4 or TSH determination on dry blood spot (dbs), respectively.

These epidemiological changes are also accompanied by a modification of the usual $\mathrm{CH}$ features. The morphogenetic defects (athyreosis, ectopy, hemiagenesis, or hypoplasia) were indeed considered to account for about $75 \%$ of total cases, while the remainder had a thyroid gland in situ (GIS) either associated with transient or permanent functional defects (Dussault, 1999; Gruters et al., 2004; Van Vliet and Czernichow, 2004; Park and Chatterjee, 2005; Rose et al., 2006; Rastogi and LaFranchi, 2010; De Felice and Di Lauro, 2011). This classification is almost completely reversed by the recent reports, as the increased $\mathrm{CH}$ incidence is mainly due to an augmented detection of hypothyroid newborns with GIS, which accounted in Lombardy for about $2 / 3$ of the examined $\mathrm{CH}$ population (Corbetta et al., 2009; Figure 1).
The possible explanations for these findings are indeed multiple (Harris and Pass, 2007; Corbetta et al., 2009; LaFranchi, 2010; Rastogi and LaFranchi, 2010; Table 1). In our case, the lower threshold for dbs-TSH screening $(10 \mathrm{mU} / \mathrm{L}$, equivalent to about $20 \mathrm{mU} / \mathrm{L}$ in serum) led to an impressive modification of $\mathrm{CH}$ epidemiology (Corbetta et al., 2009). In the last 2 years, the experience with lower TSH cutoffs was replicated in several countries including Greece and Wales (Korada et al., 2010; Mengreli et al., 2010), thus confirming the existence of numerous false negative results by using a TSH threshold for newborn recall of $20 \mathrm{mU} / \mathrm{L}$ in $\mathrm{dbs}$. These findings are the first giving support to the indication by the National Academy of Clinical Biochemistry (NACB) toward the use of lower TSH cutoffs for $\mathrm{CH}$ screening (Baloch et al., 2003). The implementation of NACB recommendation has been hampered mainly by the fear of an unjustified increase in the costs of screening programs and overload of pediatric referral centers. We estimated that the reduction of dbs-TSH cutoff in the years 1999-2005 caused an increment of $22 \%$ in the number of tests per neonate/year (Corbetta et al., 2009). This increment was the only relevant additional cost raised by the new screening strategy. Therefore, we and other consider that this effort may be justified since a previously unsuspected number of newborns with permanent "true" $\mathrm{CH}$ were detected at birth (Corbetta et al., 2009; Korada et al., 2010; Mengreli et al., 2010). In addition, the possibility to have a more careful determination of the thyroid status in neonates at moderate risk of $\mathrm{CH}$ was in our experience well-received by most of the parents.

Nevertheless, an incidence similar to those observed in Italy and Greece was reported in USA by screening $\mathrm{CH}$ with dbsT4 determination (Harris and Pass, 2007). It is therefore likely that also other factors may contribute to the increased incidence of functional thyroid defects among newborns. Certainly, ethnicity could have a role as in USA CH appears to be most and least frequent in the Asian (about 1:1,000) and Black $(1: 1,900)$ population, respectively (Harris and Pass, 2007; Rastogi and LaFranchi, 2010). Therefore, changes in the ethnic distribution of newborns may contribute to the observed rise of $\mathrm{CH}$ incidence in different countries.

Iodide deficiency is the environmental factor most widely associated with an increased prevalence of $\mathrm{CH}$. Analysis of the prevalence of dbs-TSH values above $5 \mathrm{mU} / \mathrm{L}$ (Zimmermann et al., 2005), unexpectedly revealed that one of the richest regions in Europe, such as Lombardy, is still characterized by a borderline-mild iodide deficiency during the last 10 years (5.4-6.3\%; optimal iodide supply $<3 \%$; Corbetta et al., 2009). A lowering of iodide supply, possibly linked to different feeding habits and lifestyle of immigrant populations, has been suggested also to be involved in the New York state findings (Harris and Pass, 2007). Increased iodide load as may be observed in perinatal disinfection may also lead to higher dbs-TSH values and transient $\mathrm{CH}$. However, iodide contamination is nowadays generally avoided during obstetric procedures and most of the cases with dbs-TSH values ranging $10-20 \mathrm{mU} / \mathrm{L}$ appear to be permanent (Corbetta et al., 2009; Mengreli et al., 2010).

Other mechanisms possibly contributing to the high incidence of functional defects include thyroid disrupting chemicals and premature birth. Interestingly, higher neonatal TSH values have been reported in babies born in Lombardy from mothers exposed 25 years before to dioxin contamination during the ICMESA accident in Seveso during 1976 (Baccarelli et al., 2008), suggesting that contaminants may have contributed to our findings. 


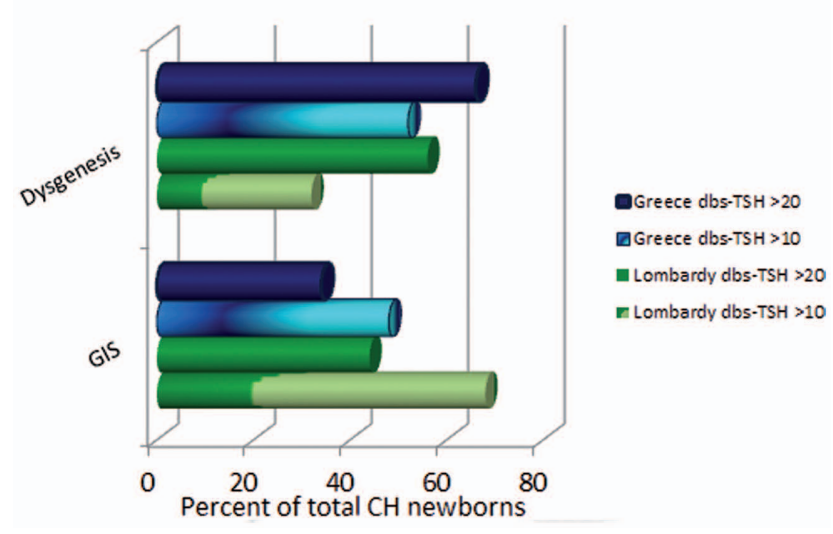

FIGURE 1 | Congenital hypothyroidism (CH) classification according to different dbs-TSH cutoff values in Greece and Lombardy. Observe the prevalence of dysgenetic $\mathrm{CH}$ using a dbs-TSH cutoff of $20 \mathrm{mU} / \mathrm{L}$ and the shift toward a higher prevalence of GIS defects in the same newborn population by lowering the dbs-TSH cutoff at $10 \mathrm{mU} / \mathrm{L}$.

Table 1 | Possible explanations for the increased incidence of $\mathrm{CH}$ newborns.

Low TSH screening cutoffs

Ethnic susceptibility (Asian and Black with highest and lowest risk, respectively)

Low/high iodine supply

Endocrine disrupting chemicals (EDCs)

Premature birth (increased risk for GIS-CH by three to fivefolds)

Multiple pregnancies

Our data revealed the frequent association of $\mathrm{CH}$ with premature birth, which represents a condition with a three to fivefold increased risk of $\mathrm{CH}$ with GIS (Corbetta et al., 2009). Children born prematurely were reported to be predisposed to nonautoimmune thyroid dysfunction as a likely consequence of the defective maturation of the hypothalamic-pituitary-thyroid axis (Radetti et al., 2007). Therefore, hypothyroidism should be included among the frequent consequences of premature birth and might contribute to the developmental defects affecting children born prematurely (van Wasseraer et al., 1997; Stoelhorst et al., 2005; LaHood and Bryant, 2007). Due to several factors, including the increased rate of multiple pregnancies, the number of premature children is diffusely growing in the recent years and survival of very pre-term infants is nowadays becoming frequent (Stoelhorst et al., 2005).

Since a defective neurological development is the main consequence of untreated CH (LaFranchi, 2010; Rastogi and LaFranchi, 2010), L-thyroxine was cautiously given to all confirmed hypothyroid infants. The indication to give an early as possible treatment to these positive infants is emphasized by the observations of an impaired psycho-neurological outcome and subtle cognitive deficits in the treated $\mathrm{CH}$ population compared to unaffected siblings (Salerno et al., 1999; Rovet, 2005; Selva et al., 2005; Oerbeck et al., 2007) and by the impaired intellectual development described in transient neonatal hypothyroidism and hyperthyrotropinemia (Calaciura et al., 1995; Azizi et al., 2001). On this basis, it is conceivable that a significant number of behavioral/neurological disorders (e.g., attention-deficit disorder) nowadays recognized later in life might be due to missed forms of neonatal CH. Since no evidence is presently available to support this view, other Authors consider at present unjustified the additional efforts to diagnose and treat milder forms of $\mathrm{CH}$ as those associated with dbs-TSH ranging 10-20 mU/L (Krude and Blankenstein, 2011).
In conclusion, the use of low dbs-TSH cutoff for neonatal screening is associated with $\mathrm{CH}$ incidence about double than previously thought. This is mainly due to the detection of hypothyroid newborns with GIS, later evolving in permanent mild thyroid dysfunction. However, other factors (ethnic modifications in the screened population, variations in iodide supply, EDCs, multiple pregnancies, and premature birth) contribute to such an increased incidence of $\mathrm{CH}$ in most recent years. Indeed, premature birth represents a high risk condition for this type of $\mathrm{CH}$. In contrast to what is currently known, inborn functional defects are noticeably prevalent over dysgenetic forms in the most recent $\mathrm{CH}$ population. Further studies are needed to define the appropriate treatment and follow-up strategy for the large group of $\mathrm{CH}$ children that evolve toward a mild thyroid dysfunction later in life.

\section{REFERENCES}

Azizi, F., Afkhami, M., Sarshar, A., and Nafarabadi, M. (2001). Effects of transient neonatal hyperthyrotropinemia on intellectual quotient and psychomotor performance. Int. J. Vitam. Nutr. Res. 71, 70-73.

Baccarelli, A., Giacomini, S. M., Corbetta, C., Landi, M. T., Bonzini, M., Consonni, D., Grillo, P., Patterson, D. G., Pesatori, A.C., and Bertazzi, P.A. (2008). Neonatal thyroid function in Seveso 25 years after maternal exposure to dioxin. PLoS Med. 5, e161. doi: 10.1371/ journal.pmed.0050161

Baloch, Z., Carayon, P., Conte-Devolx, B., Demers, L. M., Feldt-Rasmussen, U., Henry, J. F., LiVolsi, V. A., Niccoli-Sire, P., John, R., Ruf, J., Smyth, P. P., Spencer, C. A., and Stockigt, J. R. (2003). Laboratory medicine practice guidelines. Laboratory support for the diagnosis and monitoring of thyroid disease. Thyroid $13,3-126$.

Calaciura, F., Mendorla, G., Distefano, M., Castorina, S., Fazio, T., Motta, R. M., Sava, L., Delange, F., and Vigneri, R. (1995). Childhood IQ measurements in infants with transient congenital hypothyroidism. Clin. Endocrinol. (Oxf.) 43, 473-477.

Corbetta, C., Weber, G., Cortinovis, F., Calebiro, D., Passoni, A., Vigone, M. C., Beck-Peccoz, P., Chiumello, G., and Persani, L. (2009). A 7-year experience with low blood TSH cutoff levels for neonatal screening reveals an unsuspected frequency of congenital hypothyroidism (CH). Clin. Endocrinol. 71, 739-745.

De Felice, M., and Di Lauro, R. (2011). Minireview: intrinsic and extrinsic factors in thyroid gland development: an update. Endocrinology 152, 2948-2956.

Dussault, J.H. (1999). The anecdotal history of screening for congenital hypothyroidism. J. Clin. Endocrinol. Metab. 84, 4332-4334.

Gruters, A., Krude, H., and Biebermann, H. (2004). Molecular genetic defects in congenital hypothyroidism. Eur. J. Endocrinol. 151, U39-U44.

Harris, K. B., and Pass, K.A. (2007). Increase in congenital hypothyroidism in New York State and in the United States. Mol. Genet. Metab. 91, 268-277. 
Korada, S. M., Pearce, M., Ward Platt, M. P., Avis, E., Turner, S., Wastell, H., and Cheetham, T. (2010). Difficulties in selecting an appropriate neonatal thyroid stimulating hormone (TSH) screening threshold. Arch. Dis. Child. 95, 169-173.

Krude, H., and Blankenstein, O. (2011). Treating patients not numbers: the benefit and burden of lowering TSH newborn screening cut-offs. Arch. Dis. Child. 96, 121-122.

LaFranchi, S. H. (2010). Newborn screening strategies for congenital hypothyroidism: an update. J. Inherit. Metab. Dis. 33(Suppl. 2), S225-S233.

LaHood, A., and Bryant, C. A. (2007). Outpatient care of the premature infant. Am. Fam. Physician 76, 1159-1164.

Mengreli, C., Kanaka-Gantenbein, C., Girginoudis, P., Magiakou, M. A., Christakopoulou, I., GiannouliaKarantana,A., Chrousos, G. P., and Dacou-Voutetakis, C. (2010). Screening for congenital hypothyroidism: the significance of threshold limit in false-negative results. J. Clin. Endocrinol. Metab. 95, 4283-4290.

Oerbeck, B., Reinvang, I., Sundet, K., and Heyerdahl, S. (2007). Young adults with severe congenital hypothyroidism: cognitive event related potentials (ERPs) and the significance of an early start of thyroxine treatment. Scand. J. Psychol. 48, 61-67.

Park, S. M., and Chatterjee, V. K. (2005). Genetics of congenital hypothyroidism. J. Med. Genet. 42, 379-389.
Radetti, G., Fanolla, A., Pappalardo, L., and Gottardi, E. (2007). Prematurity may be a risk factor for thyroid dysfunction in childhood. J. Clin. Endocrinol. Metab. 92, 155-159.

Rastogi, M. V., and LaFranchi, S. H. (2010). Congenital hypothyrodism. Orphanet. J. Rare Dis. 5, 17.

Rose, S. R., Brown, R. S., Foley, T., Kaplowitz, P. B., Kaye, C. I., Sundararajan, S., and Varma, S. K. (2006). Update of newborn screening and therapy for congenital hypothyroidism. Pediatrics 117, 2290-2303.

Rovet, J.F. (2005). Children with congenital hypothyroidism and their siblings: do they really differ? Pediatrics 115, e52-e57.

Salerno, M., Militerni, R., Di Maio, S., Bravaccio, C., Gasparini, N., and Tenore A. (1999). Intellectual outcome at 12 years of age in congenital hypothyroidism. Eur. J. Endocrinol. 141, 105-110.

Selva, K. A., Harper, A., Downs, A., Blasco, P. A., and Lafranchi, S. H. (2005). Neurodevelopmental outcomes in congenital hypothyroidism: comparison of initial T4 dose and time to reach target T4 and TSH. J. Pediatr. 147, 775-780.

Stoelhorst, G. M., Rijken, M., Martens, S. E., Brand, R., den Ouden, A. L., Wit, J. M., Veen, S., and on behalf of the Leiden Follow-Up Project on Prematurity (2005). Changes in neonatology: comparison of two cohorts of very preterm infants (gestational age <32 weeks): the Project On Preterm and Small for Gestational Age Infants 1983 and the Leiden
Follow-Up Project on Prematurity 1996-1997. Pediatrics 115, 396-405.

Van Vliet, G., and Czernichow, P. (2004). Screening for neonatal endocrinopathies: rationale, methods and results. Semin. Neonatol. 9, 75-85.

van Wassenaer, A. G., Kok, J. H., Dekker, F. W., and deVijlder, J. J. (1997). Thyroid function in very preterm infants: influences of gestational age and disease. Pediatr. Res. 42, 604-609.

Zimmermann, M. B., Aeberli, I., Torresani, T., and Bürgi, H. (2005). Increasing the iodine concentration in the Swiss iodized salt program markedly improved iodine status in pregnant women and children: a 5-y prospective national study. Am. J. Clin. Nutr. 82, 388-392.

Received: 26 December 2011; accepted: 22 January 2012; published online: 15 February 2012.

Citation: Persani L (2012) Congenital hypothyroidism with gland in situ is more frequent than previously thought. Front. Endocrin. 3:18. doi: 10.3389/fendo.2012.00018 This article was submitted to Frontiers in Thyroid Endocrinology, a specialty of Frontiers in Endocrinology. Copyright (c) 2012 Persani. This is an open-access article distributed under the terms of the Creative Commons Attribution Non Commercial License, which permits non-commercial use, distribution, and reproduction in other forums, provided the original authors and source are credited. 